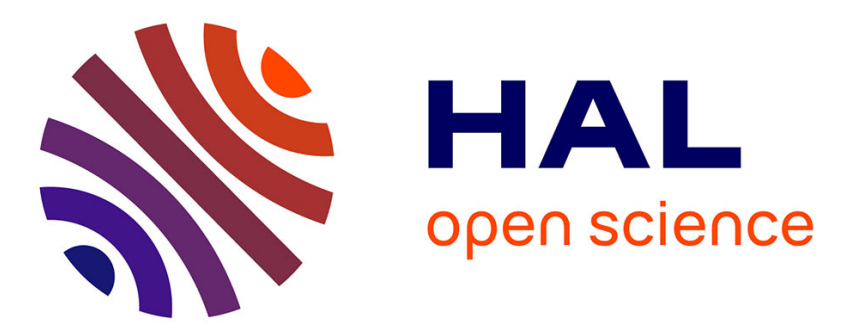

\title{
Effect of canopy removal on a rocky shore community metabolism and structure
}

Aline Migné, Claire Golléty, Dominique Davoult

\section{To cite this version:}

Aline Migné, Claire Golléty, Dominique Davoult. Effect of canopy removal on a rocky shore community metabolism and structure. Marine Biology, 2014, 162 (2), pp.449-457. 10.1007/s00227-014-2592-6 . hal-01100968

\section{HAL Id: hal-01100968 \\ https://hal.sorbonne-universite.fr/hal-01100968}

Submitted on 7 Jan 2015

HAL is a multi-disciplinary open access archive for the deposit and dissemination of scientific research documents, whether they are published or not. The documents may come from teaching and research institutions in France or abroad, or from public or private research centers.
L'archive ouverte pluridisciplinaire HAL, est destinée au dépôt et à la diffusion de documents scientifiques de niveau recherche, publiés ou non, émanant des établissements d'enseignement et de recherche français ou étrangers, des laboratoires publics ou privés. 
Effect of canopy removal on a rocky shore community metabolism and structure

$$
\text { Aline Migné }^{1,2}, \text { Claire Golléty }^{1,2,{ }^{*}} \text {, Dominique Davoult }{ }^{1,2}
$$

1- Sorbonne Universités, UPMC Univ Paris 06, Station Biologique de Roscoff, 29680 Roscoff, France

2- CNRS, UMR 7144, Station Biologique de Roscoff, 29680 Roscoff, France

* present address CUFR de Mayotte, Route Nationale 3, BP - 5397660 Dembéni, France

Corresponding author Aline Migné

migne@sb-roscoff.fr

Tel +33298292315

Fax +33298292324 
Abstract

The effects of the permanent removal of the canopy-forming alga Fucus serratus was studied in terms of both functioning and diversity on a mid-low rocky shore ecosystem in the southwest English Channel ( $\left.48^{\circ} \mathrm{N} 43.686^{\prime}, 3^{\circ} \mathrm{W} 59.282^{\prime}\right)$. Ecosystem functioning was examined as net or gross primary productivity (NPP or GPP) and respiration (Resp) measured through $\mathrm{CO}_{2}$ fluxes. Diversity was examined as number and composition of species. Measurements were performed in situ, during emersion times, without altering target assemblages. The experiment was designed with two treatments (control (C) or canopy removed (CR)) and five replicates, and was conducted over an eighteen month period (from February 2006 to August 2007) to integrate the seasonal variability. The mean GPP and Resp were severely reduced in CR treatment compared to control throughout the survey. The mean NPP was not affected at first, due to the development of opportunistic green algae, but was drastically reduced after nine months of experiment. The canopy removal affected neither the number of species nor their distribution among trophic groups and the algal community was only slightly affected. The abundance and biomass of mobile invertebrates, however, were greatly reduced in the absence of canopy. This indicates an important effect of the dominant alga on the higher trophic levels of the community. At this tidal level, the canopy did not seem to affect the community by dampening the environmental stress but by providing food, habitat or both.

Key words

Fucus serratus; intertidal; primary productivity; species diversity; in situ experiment 
Introduction

Canopy-forming algae are often found in high biomass and abundance on rocky shores and may be responsible for the major part of carbon fluxes in these systems as they represent the dominant biomass and areal cover. For example, the Ascophyllum nodosum canopy was shown to be responsible for more than $75 \%$ of the gross primary productivity and respiration of the community of a temperate mid-shore (Golléty et al. 2008). Canopy-forming algae are also key structural elements that modify the environment and influence the occurrence of other species. The net canopy effect on the structure of intertidal communities results from the interplay of positive and negative influences (Beermann et al. 2013) and depends on the elevation on the shore (Watt and Scrosati 2013b). For example, understory organism recruitment, growth, and survival may be enhanced by algal canopy reducing the physical stress in high rocky intertidal communities, while they may be reduced by algal canopy increasing the consumer pressure in low intertidal communities (Bertness et al. 1999). Furthermore, the presence of a canopy-forming alga may promote the community stability by dampening the environmental condition oscillations (Bulleri et al. 2012). Rocky shore canopy-forming algae are susceptible to loss through various natural and anthropogenic stressors on coastal ecosystems and the loss of a single canopy species can lead to cascading effects on other species of the community and have severe consequences on its functioning (Schiel 2006).

The community effects of a canopy-forming alga removal have been widely studied in terms of number, composition and abundance of associated species and a large range of responses has been observed (Crowe et al. 2013). The response depends on complex interactions among species and local abiotic conditions. Even if the replacement by a less competitive but functionally similar species can occur, the removal of a canopy-forming alga may have important effects on the community structure. For example, canopies of Fucus serratus and $F$. vesiculosus developed after the removal of $A$. nodosum in a British shore and the balance between grazing limpets and the cover of red algal turf in the understory community changed (Jenkins et al. 2004). The removal of the canopyforming species will have even more important effects on the structure of the community if no replacement occurs. In some mid-intertidal systems of southern New Zealand, Hormosira banksii is the only fucoid able to withstand the high thermal stress, so that its removal was not compensated and led to the loss of almost the entire epifaunal community (Lilley and Schiel 2006). Less research has considered the potential consequences of the removal of canopy-forming algae on primary productivity. In the absence of functional replacement of the macroalga, however, a severe reduction in primary productivity may be expected (Tait and Schiel 2011; Crowe et al. 2013). Another aspect that has been poorly explored is the role that canopy-forming algae can play in the temporal variability of community metabolism (Valdivia et al. 2012). The stability of community functional 
properties may be related to the dominance of large perennial species, with the outcome depending on the dominant species' identity (Hillebrand et al. 2008) and on the environmental context (Grman et al. 2010).

Previous studies have demonstrated that the response of rocky shore communities to the loss of canopy species can vary dramatically due to variable combinations of abiotic and biotic factors. The functional consequences of changes in the community structure needs to be measured in the field to realistically take into account this combination of factors. The present study examined the effects of the permanent removal of the canopy-forming alga Fucus serratus on a mid-low rocky shore ecosystem both in terms of diversity (number and composition of species) and functioning (primary productivity and respiration). $\mathrm{CO}_{2}$ fluxes were measured directly in situ, without altering target assemblages, over a period integrating the seasonal variability. The aim of this field experiment was (1) to test whether the loss of the canopy alga would reduce the community primary productivity and respiration level and affect their temporal variation, (2) to determine how the absence of this canopy might modify the composition of the community and its temporal variation and (3) to examine the links between community composition and metabolism.

\section{Materials and methods}

Study site

The study site $\left(48^{\circ} \mathrm{N} 43.686^{\prime}, 3^{\circ} \mathrm{W} 59.282^{\prime}\right)$ is in front of the Station Biologique de Roscoff, southwest of the English Channel (Brittany, France), where the extreme high water of spring tide is situated at $9.85 \mathrm{~m}$ above Chart Datum [C.D.]. This is a sheltered area of stacked boulder field, characterized from mean low water neap tide ( $3.25 \mathrm{~m}$ above C.D.) to mean low water spring tide (1.15 m above C.D.), by a dense cover of the fucoid Fucus serratus.

\section{Experimental design and set-up}

The experiment, designed with two treatments (control (C) or canopy removed (CR)) and five replicates, was conducted during an eighteen month period (from February 2006 to August 2007). All manipulations, measurements and observations were performed during emersion times. Ten $0.09 \mathrm{~m}^{2}$ quadrats with at least $75 \%$ Fucus serratus cover were marked with stainless steel screws. At the start of the experiment, all $F$. serratus were removed with a knife from 5 randomly selected quadrats and from a $50 \mathrm{~cm}$ wide band around them. Canopy removal was maintained throughout the experiment, simulating an extended period of canopy loss. 
Community metabolism was examined by the measurement of $\mathrm{CO}_{2}$ fluxes at the rock-air interface using benthic chambers. Measurements were performed on each quadrat four, six, nine, twelve and eighteen months after the initial removal of the canopy. The benthic chamber consisted of a transparent Plexiglass dome and a $0.09 \mathrm{~m}^{2}$ transparent plexiglass base, air-tightly sealed with neutral silicone, for a total volume of $18.9 \mathrm{~L}$. Changes in $\mathrm{CO}_{2}$ mol fraction (ppm) were measured by an infrared $\mathrm{CO}_{2}$ gas analyser (LI-COR, LI-800) and recorded every $15 \mathrm{~s}$ with a data logger (LI-COR, LI1400) during 5-20 min incubations as described by Migné et al. (2002). $\mathrm{CO}_{2}$ fluxes were calculated from the slope of $\mathrm{CO}_{2}$ concentration $\left(\mu \mathrm{mol}_{\mathrm{CO} 2} \mathrm{~mol}_{\text {air }}{ }^{-1}\right.$ ) against time (min). Results were then expressed in carbon units ( $\mathrm{mmolC}{ }^{-2} \mathrm{~h}^{-1}$ ) assuming a molar volume of $22.4 \mathrm{~L} \mathrm{~mol}^{-1}$ at standard temperature and pressure. Measurements were performed under ambient light to assess the rate of benthic community net primary productivity (NPP) and in darkness, by covering the chamber with an opaque polythene sheet, to assess benthic community respiration (Resp). Benthic community gross primary productivity (GPP) was then calculated as the sum of NPP and Resp. Care was taken to perform the measurements under light at saturating irradiance levels. Irradiance was measured at the rock surface as PAR (Photosynthetically Available Radiation) using a LiCor SA-190 quantum sensor. A threshold of PAR of $300 \mu \mathrm{mol} \mathrm{m}{ }^{-2} \mathrm{~s}^{-1}$ was chosen based on the average value of $291 \mu \mathrm{mol}$ $\mathrm{m}^{-2} \mathrm{~s}^{-1}$ given for the onset of light saturation of coastal macroalgal communities by Middelboe et al. (2006). Working at saturating irradiance levels enables valid comparisons between treatments and times despite variations in irradiance.

Before the CR treatment was initiated, all macro-epi-benthic specimens were identified to the lowest taxonomic level possible in the field (usually species). The percentage cover of each alga was estimated using an index (1: ]0-25\%], 2: ]25-50\%], 3: ]50-75\%], 4: ]75-100\%]) and the solitary animals were counted in all 10 quadrats. This was repeated the following day in the 5 quadrats from which the canopy was removed and three, six, nine, twelve, sixteen and eighteen months later in the 10 quadrats. Biomass was sampled destructively at the end of the experiment, kept separately for the different taxa, and measured as dry weight.

Data analysis

Rate of community metabolism (NPP, Resp and GPP) measured for each treatment was compared at each period of measurement. Furthermore, the temporal variation in community metabolism (GPP and Resp) was assessed by calculating the coefficient of variation (Standard Deviation (SD)/mean) for each quadrat along the survey.

As the number of taxa per quadrat was low, diversity was analysed at the five quadrat scale $\left(0.45 \mathrm{~m}^{2}\right.$; i.e. at each period, the data of the five quadrats of each treatment were pooled) using either univariate or multivariate descriptors. Univariate descriptors included total number of taxa (S) 
as well as Shannon's diversity index $(\mathrm{H}$, using logarithm to the base 2$)$ and Pielou's evenness $(\mathrm{J})$ calculated for solitary counted animals. Multivariate descriptors corresponded to community composition. Samples were compared using non-metric multidimensional scaling (MDS) based on Bray-Curtis similarities. Both presence-absence and occurrence data (corresponding to the number of quadrats among five in which the taxon was observed) were used to analyse the whole community. Cover data were used to analyse the algal community (Fucus serratus excluded). Abundance data were used to analyse the solitary counted animal community. Community composition was also analysed at the quadrat scale to estimate its temporal variation using the average Bray-Curtis similarity for each quadrat over time.

\section{Statistical tests}

The absence of difference in $\mathrm{S}, \mathrm{H}$ and $\mathrm{J}$ between $\mathrm{C}$ and $\mathrm{CR}$ quadrats before the canopy was removed was verified using a Student's t- test. A student's t-test was also used to test for a difference between C and CR quadrats in (1) NPP at the different periods of observation, (2) temporal variation of Resp and GPP (assessed by the coefficient of variation over time), (3) temporal variation of community composition (assessed by the Bray-Curtis similarity over time), and (4) algal biomass (other than F. serratus) and per-biomass gross productivity at the end of the experiment. Univariate descriptors of diversity obtained in each treatment along the survey were compared using paired Student's t-test. All these tests were performed after the normality of data was verified (Shapiro test, $P>0.05)$. The data of per-biomass productivity measured at the end of the experiment were logtransformed to meet the normality assumption. The Welch correction was applied if the homogeneity of variances was not verified (Fisher test, $P<0.05$ ). This was necessary only to test for differences in community net primary productivity after six months of experiment and in perbiomass gross productivity at the end of the experiment. The difference between $\mathrm{C}$ and $\mathrm{CR}$ treatments in the distribution of taxa among trophic types was tested using a Chi-square test.

\section{Results}

Community metabolism

The removal of the Fucus serratus canopy led to a severe decline in both community gross primary productivity (GPP) and community respiration (Resp) throughout the survey. The mean GPP rates were 2 to 19 times lower in the experimental quadrats than in the control ones (Figure 1a), whereas the mean Resp rates were 5 to 25 times lower (Figure 1b). The mean community net primary productivity was reduced in the canopy removed quadrats after nine months until the end of the experiment, but was not significantly different between the two treatments four and six months 
after the experiment was initiated ( $\mathrm{t}$ test, $t 8=1.078, P=0.312$ and $t 4.3=0.673, P=0.536$ respectively, Figure 1c).

The removal of the canopy also led to a significant increase in the temporal variation of the GPP ( $t$ test, $t 8=5.083, P<0.001$ ) while it did not affect significantly the temporal variation of the Resp ( $t$ test, $t 8=1.481, P=0.177$, Figure 2 ).

Community structure

As a whole, 67 taxa were observed during the survey: 26 algae (14 of them common to the two treatments, 6 exclusive to the control and the canopy removed treatments respectively) and 41 animals (17 of them common to the two treatments, 14 exclusive to control and 10 to canopy removed treatment). Among exclusive to the $C$ treatment were sessile species mainly epiphytic on Fucus serratus: the algae Ceramium sp. and Polysiphonia sp., the hydroids Dynamena pumila and Laomedea sp., the bryozoan Electra pilosa and the colonial ascidian Botrylloïdes leachi, and a mobile species inhabiting F. serratus fronds, the isopod Dynamene bidentata. Among exclusive to the CR treatment were primary space holders (that could have benefitted from the absence of the dominant species): the algae Himanthalia elongata, Mastocarpus stellatus and Lithophyllum incrustans, the sea anemone Actinia equina and the gastropod Patella vulgata. The distribution of the whole community among trophic types (autotroph, grazer, suspension-feeder and predator) was not significantly different between the two treatments (Chi-square, $X 3=0.852, P=0.837$, Figure 3 ). Across sampling dates, the mean number of taxa ( $\pm S D, n=7$ ) was $23 \pm 5$ in the $C$ treatment and $22 \pm 4$ in the CR treatment, which was not significantly different (Paired t test, $t 6=1.030, P=0.343$ ).

When the whole community was considered, the non-metric multidimensional scaling did not evidence a clear separation between the two treatments using presence/absence data (Figure 4a) but did separate the two treatments using occurrence data (except for the sample CRO, taken just after the removal of the canopy, which was grouped with the $C$ samples, Figure $4 \mathrm{~b})$. When considering the algal community only (using cover data without Fucus serratus), the two treatments were not separated either (Figure 4c). In contrast, a clear effect of canopy removal was shown on the community structure of counted animals (Figure $4 d$ ).

A total of 29 solitary animals were counted during the survey, 12 of them common to the two treatments, 9 and 8 exclusive to the control and the canopy removed treatments respectively. The mean $( \pm S D)$ number of animal taxa was the same in the two treatments $(9 \pm 2, n=7)$ but the number of individuals was higher (Paired t test, $t 6=13.314, P<0.001$ ) and diversity and evenness lower (Paired t test, $t 6=4.003$ and 4.757 respectively, $P<0.01$ ) in the control (Figure 5 ). The community was dominated by grazing gastropods, particularly Gibbula pennanti which density $( \pm$ SD, 
$n=7$ ) averaged $312 \pm 76$ ind $\mathrm{m}^{-2}$ and accounted for $71 \%$ of the total density in the C quadrats while it averaged $44 \pm 19$ ind $\mathrm{m}^{-2}$ and accounted for $50 \%$ of the total density in the CR quadrats.

The removal of the canopy also altered the temporal variation of the entire community structure (Figure 6). Species fluctuation was increased, as shown by the significant decrease in average Bray-Curtis similarity for each replicate quadrat over time, when considering the presence/absence data for the whole community ( $t$ test, $t 8=4.073, P<0.01$ ). Fluctuations in the abundance of individual species within the counted animal community were also increased, as the average Bray-Curtis similarity was significantly lower in CR than in C treatment ( $\mathrm{t}$ test, $t 8=2.434, P<$ 0.05). There was, however, no significant difference in average Bray-Curtis similarity for each replicate quadrat over time considering the cover data for the algal community (Fucus serratus excluded, $\mathrm{t}$ test, $t 8=0.700, P=0.504)$.

Ephemeral algae (U/va) settled in spring. In May, that is three months after the experiment was initiated, it covered more than $75 \%$ of the surface area in CR quadrats while it was absent from C quadrats (Figure 7). The following year, the development was less important and similar in the two treatments (between 25 and 50\% cover in June).

At the end of the experiment, both algal and animal biomasses were greatly higher in $\mathrm{C}$ than CR quadrats (Table 1). The biomass of algae without Fucus serratus, however, did not differ significantly between treatments ( $\mathrm{t}$ test, $t 8=0.084, P=0.935$ ).

\section{Discussion}

This field experiment confirmed that the loss of a canopy alga can reduce dramatically the community primary productivity, community respiration and community biomass. As the canopy was suspected to be responsible for the major part of the community metabolism of such rocky shores (Golléty et al. 2008), the severe decrease in both gross primary productivity and respiration observed in the canopy removal treatment was expected. As observed in the preliminary work of Hawkins and Harkin (1985), however, the removal of Fucus serratus allowed the development of ephemeral green algae. Such species are characterized by a higher productivity (on a per-biomass basis) than perennial ones (Littler and Arnold 1982) and their blooming should lead to relatively high per area productivity. Indeed, the cover of opportunistic green algae limited the decrease in productivity three and six months after the removal of the canopy such that the net productivity of the community was not affected by the treatment initially. Nevertheless, after nine months of experiment, the net productivity of the community was drastically reduced in the absence of the canopy and this was still observed after twelve and eighteen months. The dominant large brown alga of this shore then appeared to be irreplaceable as a contributor to the community metabolism, as also shown for the same species on two other rocky shores of northern Europe (Crowe et al. 2013). The per-biomass 
community gross productivity measured at the end of the experiment, however, was not significantly

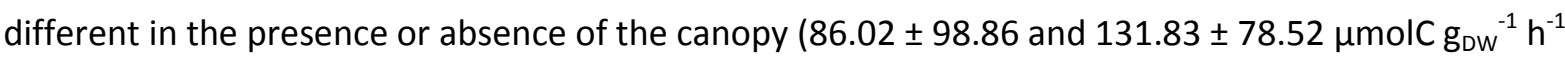
respectively, $\mathrm{t}$ test, $t 4.8=1.515, P=0.192$ ). This showed that Fucus serratus had a major role in the community primary productivity due to its high biomass but not due to a specifically high productivity, in contrast to the dominant fucoids of southern New Zealand mid and low shores (Tait and Schiel 2011). Furthermore, the total biomass of other algae at the end of the experiment was not affected by the absence of the canopy. This might result from the balance between positive and negative influences of the canopy on the local environment under emerged and immersed conditions. Canopies reduce desiccation, temperature and light stress in the air at low tide, while they increase light limitation in water to the understory algae at high tide. In contrast, the removal of the canopy greatly decreased the animal biomass, showing an important effect on higher trophic levels.

The removal of the canopy alga led to an increase in temporal variation of gross primary productivity, which could be explained by the increased blooming of ephemeral green algae during the first year of experiment. Nevertheless, the temporal variation of respiration, a process reflecting the resource use by the whole community, was not affected by the canopy removal: a similar seasonal trend was observed for the two treatments (Figure 1b). This shows the predominant role of seasonally variable parameters (such as temperature) in the control of respiration of both canopy and other species, leading to synchronous variation in metabolic activity. An evidence of the control of respiration rate by temperature for both total and understory communities has already been given for another fucoid stand of the same area (Golléty et al. 2008). In this previous study, measurement of the understory respiration rate was only performed just after the canopy was removed. The present result, obtained with an extended period of canopy loss, shows that the seasonal variation of temperature was not sufficiently dampened by the canopy to modify the seasonal trend of the understory community metabolism. The canopy did not then enhance the stability of this community aggregate property. This result is in accordance with the study of Bulleri et al. (2012), which showed that Fucus serratus had a weak effect on the temporal variability of the sessile species cover (used as a proxy for biomass) in North Atlantic rocky shores, in contrast to Ascophyllum nodosum (a mid-level species) and to the canopies in Southern Europe.

The canopy removal affected neither the number of species nor their distribution among trophic groups. This may indicate that the environmental stress was not increased in this mid-low shore experiment, which would have led to decreasing the number of species and changing their distribution among trophic groups (Scrosati et al. 2011). The canopy removal had little effect on the structure of the algal community. The greater cover attained by ephemeral green algae in canopy 
removal treatment related to control in the first year of the experiment may have resulted from competitive release through canopy absence. The absence of difference between treatments sixteen and eighteen months after the onset of the experiment, however, suggests that interactions with other species in the community were involved. The single canopy removal effect shown in this study was on the associated invertebrates. The species richness of animals did not differ between quadrats with and without Fucus serratus and only few species were clearly confined to quadrats with $F$. serratus, but the assemblages differed consistently and the total animal abundance and biomass were greatly reduced in the absence of canopy. The gastropod grazers, living mainly on the $F$. serratus fronds, were particularly affected. The canopy removal decreased the density of the dominant species, Gibbula pennanti, increasing the evenness (and then the diversity) in the mobile invertebrate community.

Canopies have been shown to affect community differently along the intertidal gradient. In a manipulative experiment, species richness, diversity and composition were affected by the fucoid canopy at the high and mid intertidal zones (richness and diversity being enhanced in the presence of canopy) but not at the low intertidal zone (Watt and Scrosati 2013a). This result was confirmed by a regional-scale study (Watt and Scrosati 2013b). This implied that the canopy effects on the structure of intertidal community were mediated by the environmental stress. The capacity of fucoid canopies to enhance richness and diversity should be related to their ability to improve conditions in stressful environments but limited to high and mid shores. Tait and Schiel (2011) showed, however, an obvious change in community composition following the canopy removal at both mid and low shores. At mid-tide level, newly exposed understory algae became desiccated and died off, confirming the environment amelioration by the canopy in this thermally stressed shore. At low-tide level, proportions shifted between species in the assemblage, involving a role of the canopy in the species interactions. In the present study, the canopy was shown to reduce the diversity of mobile invertebrates in the low shore by increasing the dominance of one species.

The greater number of grazers observed in the control compared to the canopy removal treatment is consistent with observations made by Ingolfsson (2008) in the south-western Iceland. Comparing community composition where F. serratus is the dominant alga to the adjacent area where it is absent, he found a greater attractiveness to $F$. serratus than to other species for grazers. This may be partly explained by the abundance of understory algae, although the grazers considered may also prefer $F$. serratus to other species. In the present study, since the assemblage of algae did not differ in the absence of $F$. serratus, the canopy effect on invertebrates might be direct. It may be hypothesized that this direct effect is related to the high canopy biomass and cover that supply food to primary consumers or to its structural complexity that increases secondary-space availability and provides refuge from predation. The absence of canopy effect on algal community (in terms of 
species richness, composition and biomass) might also result from the interplay between abiotic and biotic influence. Canopy might reduce the stress of aerial exposure but might also increase the grazing pressure by providing space and refuge to grazers. Physical (thermal and desiccation) stressors and herbivores have been shown to have independent, additive effects on seaweed abundance and diversity in an upper- and mid-intertidal rocky shore of California, on a site more benign compared to the North Atlantic (Williams et al. 2013). Complementary studies involving experimental manipulations of these two factors would be necessary to test for their combined influence in the mid-low Fucus serratus zone of the North Atlantic coast.

The canopy removal increased the temporal fluctuation of the community species composition but had no effect on the fluctuations in cover of the individual algal species, indicating the absence of compensatory dynamics within the algal community. Asynchronous compensatory dynamics among algal species should have been expected if the environment variability had been increased as a consequence of the canopy removal (Valdivia et al. 2012). This might again suggest that the dampening effect of the canopy on environmental variations was weak in this mid-low rocky shore and not sufficient to modify the algae dynamic. Although the changes within the algal community were not affected, the canopy removal increased the temporal variability in the abundances of the individual mobile invertebrate species, which indicates a direct effect of the canopy on higher trophic levels.

This experimental study showed some significant effects of the dominant canopy-forming alga on the structure and the functioning of the rocky-shore community. Not only were the primary productivity and respiration greatly reduced in the absence of the canopy but also the biomass of associated mobile invertebrates. This indicates an important effect of the dominant alga on higher trophic levels of the community, even if neither the number of species nor their distribution among trophic groups was affected. In addition, community gross primary productivity and community structure were shown to be more temporarily variable after the canopy removal. The canopy did not seem to affect the community by dampening the environmental stress but by providing food, habitat or both. Further experimental works would be necessary to disentangle the species interactions involved.

\section{Acknowledgments}

This experiment was conducted in the framework of the MarBEF responsive mode project BIOFUSE, led by T. Crowe and L. Benedetti-Cecchi. Thanks are due to colleagues and students who helped carry out the field work and particularly to R. Michel (the most famous "siliconeur") and C. Broudin. 
References

Beermann AJ, Ellrich JA, Molis M, Scrosati RA (2013) Effects of seaweed canopies and adult barnacles on barnacle recruitment: The interplay of positive and negative influences. Journal of Experimental Marine Biology and Ecology 448: 162-170

Bertness MD, Leonard GH, Levine JM, Schmidt PR, Ingraham AO (1999) Testing the relative contribution of positive and negative interactions in rocky intertidal communities. Ecology 80: $2711-2726$

Bulleri F, Benedetti-Cecchi L, Cusson M, Maggi E, Arenas F, Aspden R, Bertocci I, Crowe TP, Davoult D, Eriksson BK, Fraschetti S, Golléty C, Griffin JN, Jenkins SR, Kotta J, Kraufvelin P, Molis M, Pinto IS, Terlizzi A, Valdivia N, Paterson DM (2012) Temporal stability of European rocky shore assemblages: variation across a latitudinal gradient and the role of habitat-formers. Oikos 121: 1801-1809

Crowe TP, Cusson M, Bulleri F, Davoult D, Arenas F, Aspden R, Benedetti-Cecchi L, Bevilacqua S, Davidson I, Defew E, Fraschetti S, Golléty C, Griffin JN, Herkuel K, Kotta J, Migné A, Molis M, Nicol SK, Noël LMLJ, Pinto IS, Valdivia N, Vaselli S, Jenkins SR (2013) Large-scale variation in combined impacts of canopy loss and disturbance on community structure and ecosystem functioning. PloS one 8: e66238

Golléty C, Migné A, Davoult D (2008) Benthic metabolism on a sheltered rocky shore: Role of the canopy in the carbon budget. Journal of Phycology 44: 1146-1153

Grman E, Lau JA, Schoolmaster DR, Jr., Gross KL (2010) Mechanisms contributing to stability in ecosystem function depend on the environmental context. Ecology Letters 13: 1400-1410

Hawkins SJ, Harkin E (1985) Preliminary canopy removal experiments in algal dominated communities low on the shore and in the shallow subtidal on the Isle of Man. Botanica Marina 28: 223-230

Hillebrand H, Bennett DM, Cadotte MW (2008) Consequences of dominance: A review of evenness effects on local and regional ecosystem processes. Ecology 89: 1510-1520

Ingolfsson A (2008) The invasion of the intertidal canopy-forming alga Fucus serratus L. to southwestern Iceland: Possible community effects. Estuarine Coastal and Shelf Science 77: $484-490$

Jenkins SR, Norton TA, Hawkins SJ (2004) Long term effects of Ascophyllum nodosum canopy removal on mid shore community structure. Journal of the marine biological Association of the United Kingdom 84: 327-329

Lilley SA, Schiel DR (2006) Community effects following the deletion of a habitat-forming alga from rocky marine shores. Oecologia 148: 672-681 
Littler MM, Arnold KE (1982) Primary productivity of marine algal functional-form groups from southwestern North America. Journal of Phycology 18: 307-311

Middelboe AL, Sand-Jensen K, Binzer T (2006) Highly predictable photosynthetic production in natural macroalgal communities from incoming and absorbed light. Oecologia 150: 464-476

Migné A, Davoult D, Spilmont N, Menu D, Boucher G, Gattuso J-P, Rybarczyk H (2002) A closedchamber $\mathrm{CO}_{2}$-flux method for estimating intertidal primary production and respiration under emersed conditions. Marine Biology 140: 865-869

Schiel DR (2006) Rivets or bolts? When single species count in the function of temperate rocky reef communities. Journal of Experimental Marine Biology and Ecology 338: 233-252

Scrosati RA, van Genne B, Heaven CS, Watt CA (2011) Species richness and diversity in different functional groups across environmental stress gradients: a model for marine rocky shores. Ecography 34: 151-161

Tait LW, Schiel DR (2011) Legacy Effects of Canopy Disturbance on Ecosystem Functioning in Macroalgal Assemblages. Plos One 6: e26986

Valdivia N, Golléty C, Migné A, Davoult D, Molis M (2012) Stressed but stable: canopy loss decreased species synchrony and metabolic variability in an intertidal hard-bottom community. PloS one 7: e36541

Watt CA, Scrosati RA (2013a) Bioengineer effects on understory species richness, diversity, and composition change along an environmental stress gradient: Experimental and mensurative evidence. Estuarine Coastal and Shelf Science 123: 10-18

Watt CA, Scrosati RA (2013b) Regional consistency of intertidal elevation as a mediator of seaweed canopy effects on benthic species richness, diversity, and composition. Marine Ecology Progress Series 491: 91-99

Williams SL, Bracken MES, Jones E (2013) Additive effects of physical stress and herbivores on intertidal seaweed biodiversity. Ecology 94: 1089-1101 

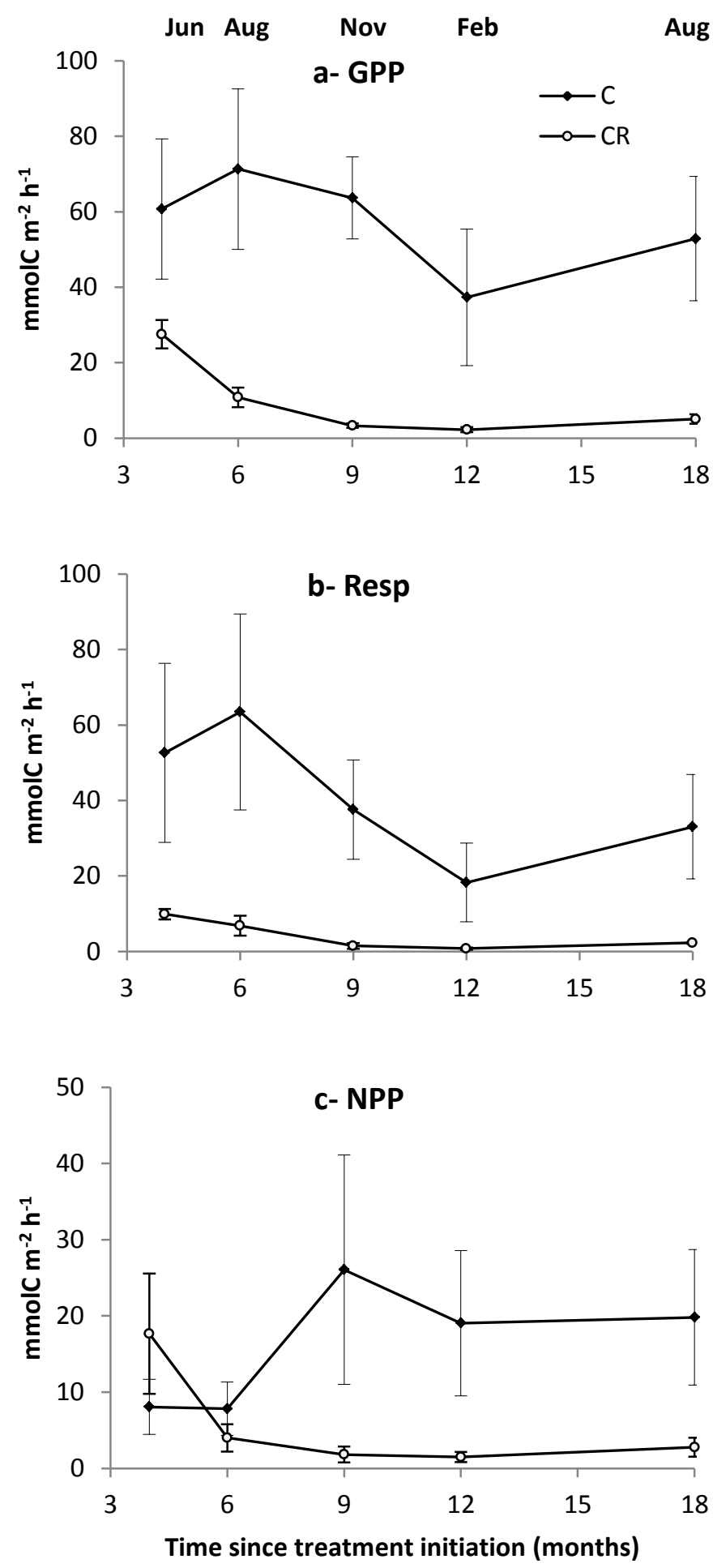

Figure 1: Mean $( \pm S E)$ gross primary productivity $(G P P, a)$, respiration (Resp, b) and net primary productivity (NPP, c) measured in mmolC $\mathrm{m}^{-2} \mathrm{~h}^{-1}$ in control (C) and canopy removed (CR) quadrats, 4 $(n=5), 6(n=5), 9(n=3), 12$ ( $n=4$ for $C$ and $n=5$ for CR) and $18(n=5)$ months after initial removal (corresponding months of measurement indicated above) 


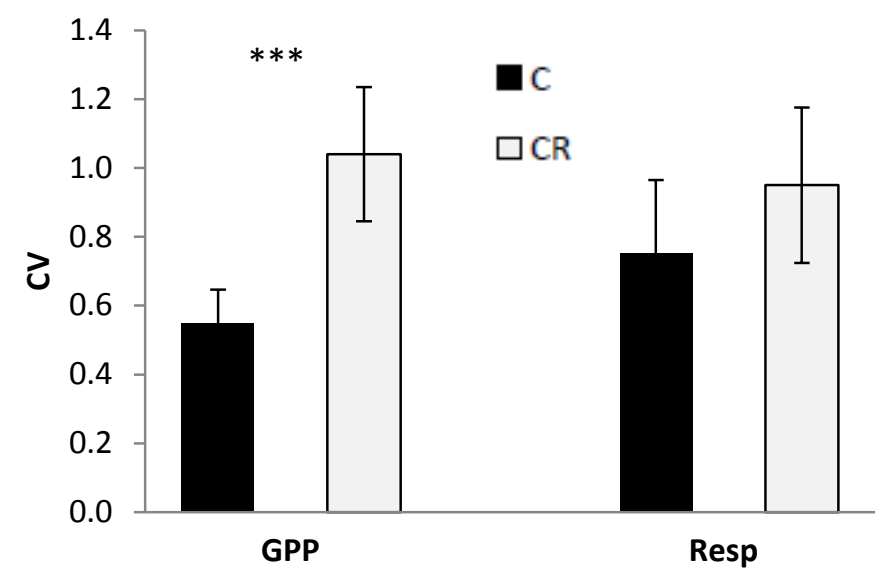

Figure 2: Mean ( \pm SD, $n=5$ ) coefficient of temporal variation (CV) of gross primary productivity (GPP) and respiration (Resp) in control (C) and canopy removed (CR) quadrats. Asterisks indicate a significant difference between treatments with $P<0.001$

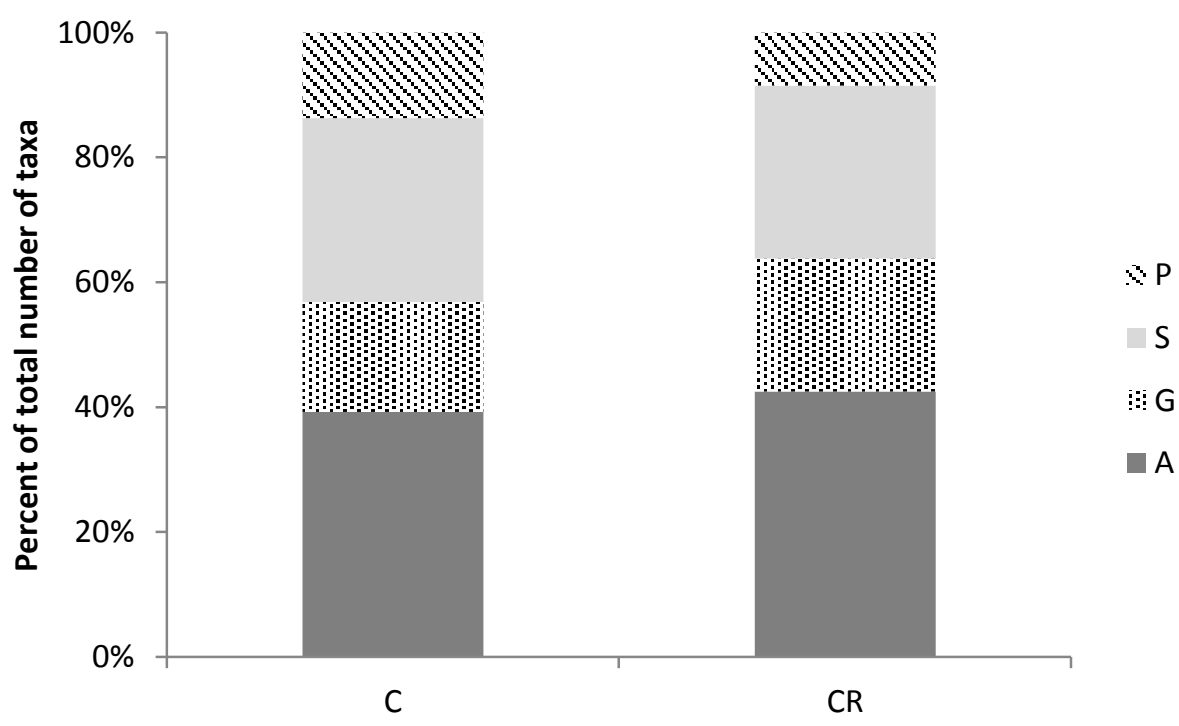

Figure 3: Repartition of taxa among trophic types (A: autotroph, G: grazer, S: suspension-feeder, P: predator) in control (C) and canopy removed (CR) treatments 
a. All taxa (pres/abs)

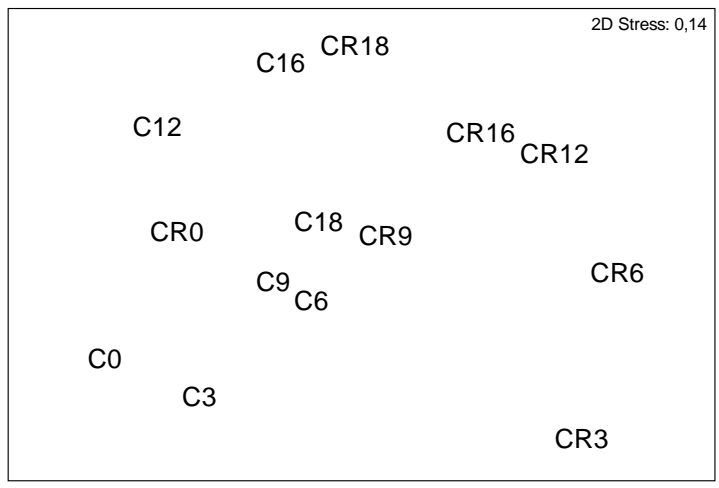

c. Algae (cover)

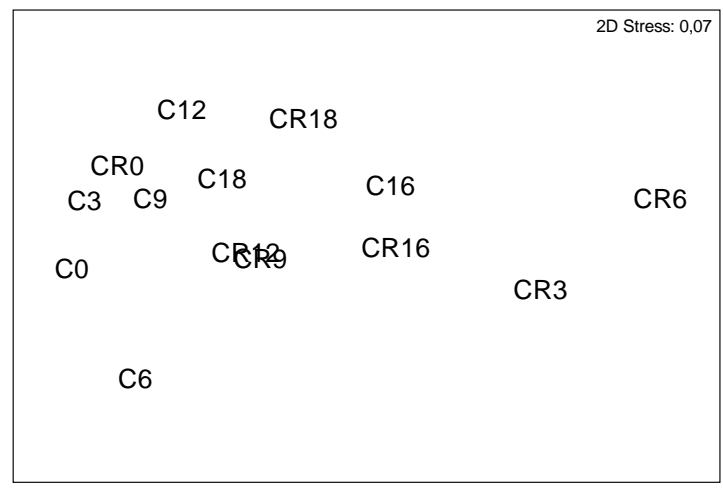

b. All taxa (occurrence)

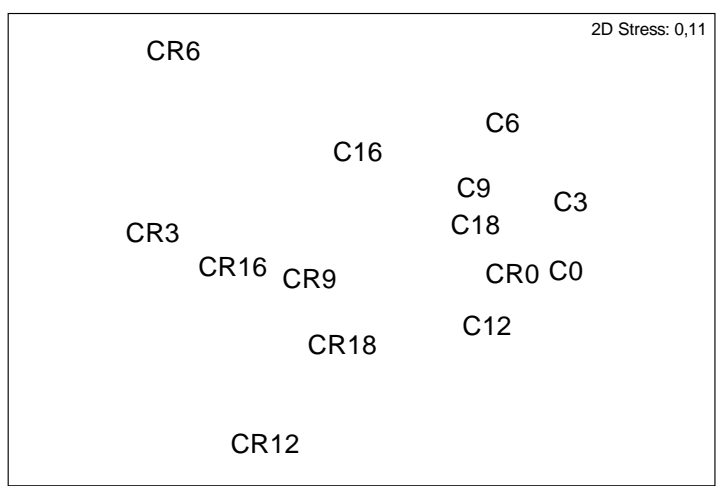

d. Animals (abundance)

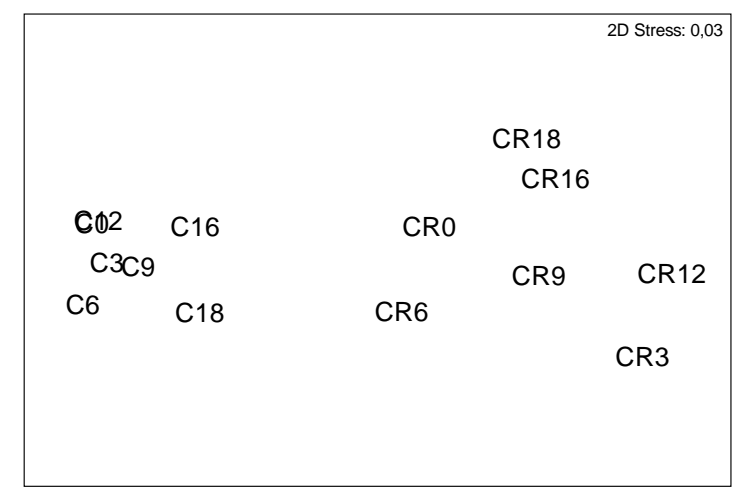

Figure 4: Two-dimensional non-metric multidimensional scaling plots showing variation in community composition through time in control (C) and canopy removed (CR) treatments (each number represents the months after initial removal). a. All taxa, presence-absence data; b. All taxa, occurrence data (corresponding to the number of quadrats in which the taxon was observed); $c$. algae (Fucus serratus excluded), cover data; d. solitary counted animals, abundance data 

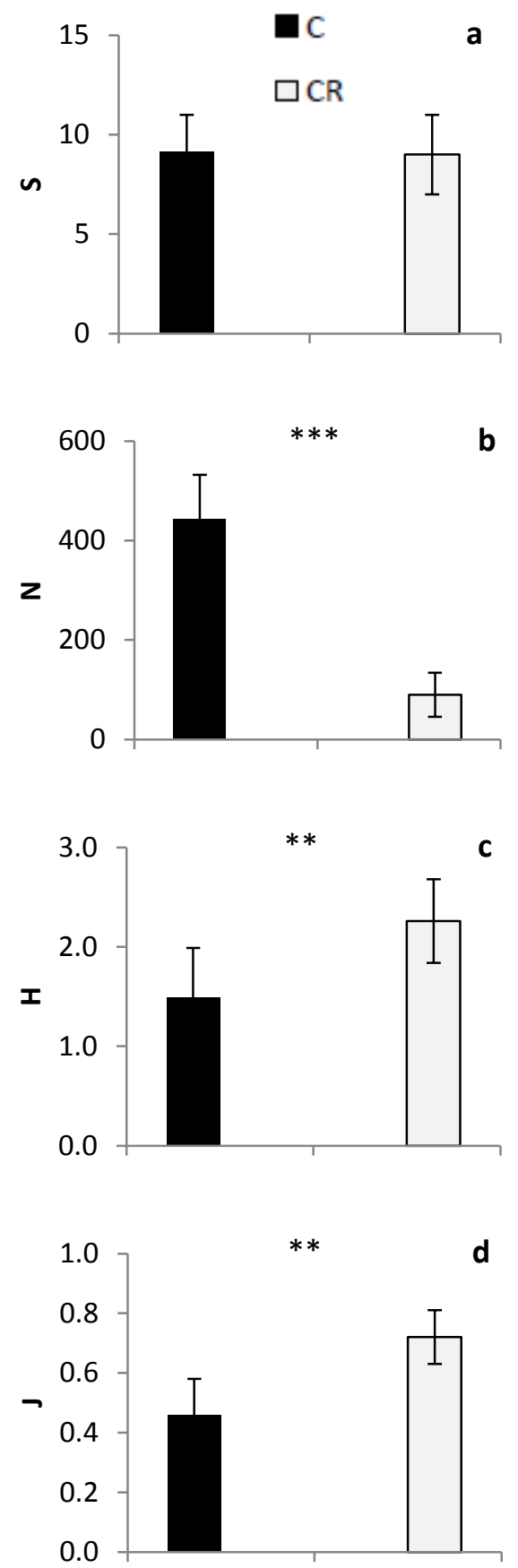

Figure 5: Comparison of solitary counted animals in control (C) and canopy removed (CR) treatments: a. number of taxa $(S)$; b. number of individuals per $\mathrm{m}^{2}(\mathrm{~N})$; c. Shannon diversity index $(H)$; d. Pielou's evenness $(J)$. All values are mean $( \pm S D)$ of data obtained at the 5 -quadrat scale $\left(0.45 \mathrm{~m}^{2}\right)$ along the survey, $n=7$. Asterisks indicate significant differences between treatments $\left({ }^{* * *} P<0.001, * * P<\right.$ $0.01)$ 


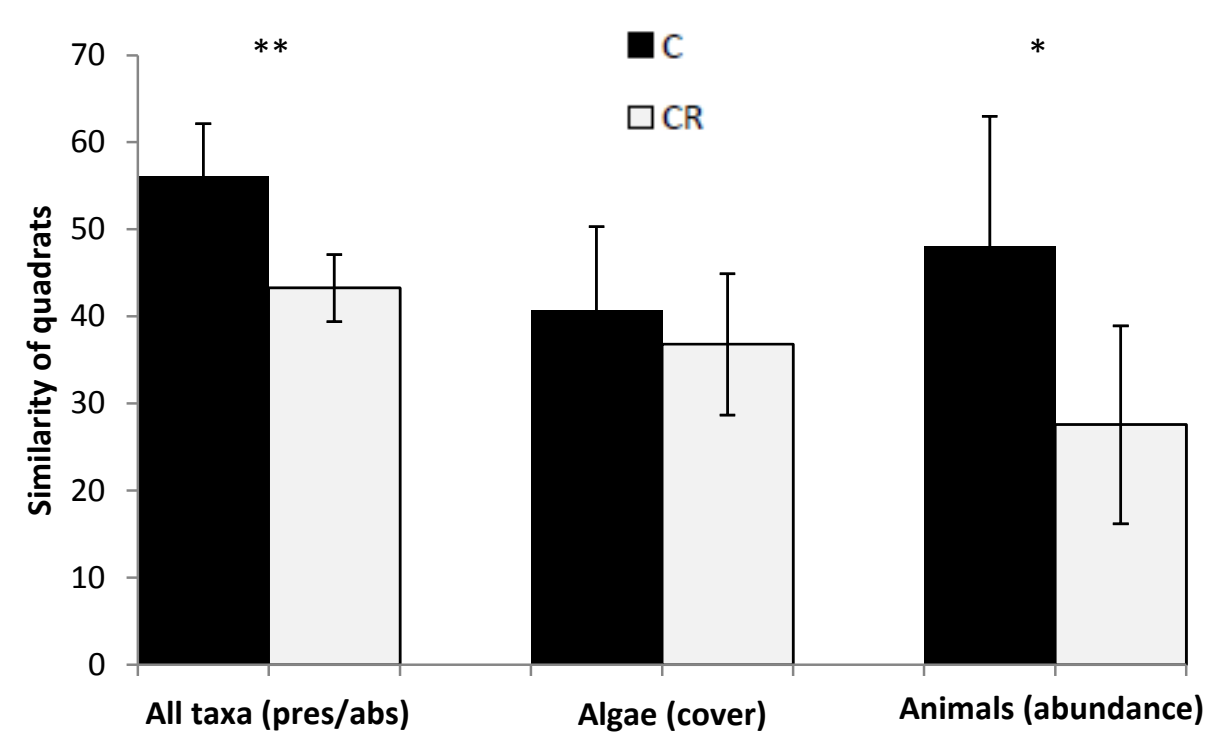

Figure 6: Mean ( $\pm S D, n=5)$ Bray-Curtis similarity for each replicate quadrat over time in control (C) and canopy removed (CR) treatments, calculated on presence-absence data for all taxa, cover data for algae (Fucus serratus excluded) and abundance data for counted animals. Asterisks indicate significant differences between treatments $(* * P<0.01, * P<0.05)$

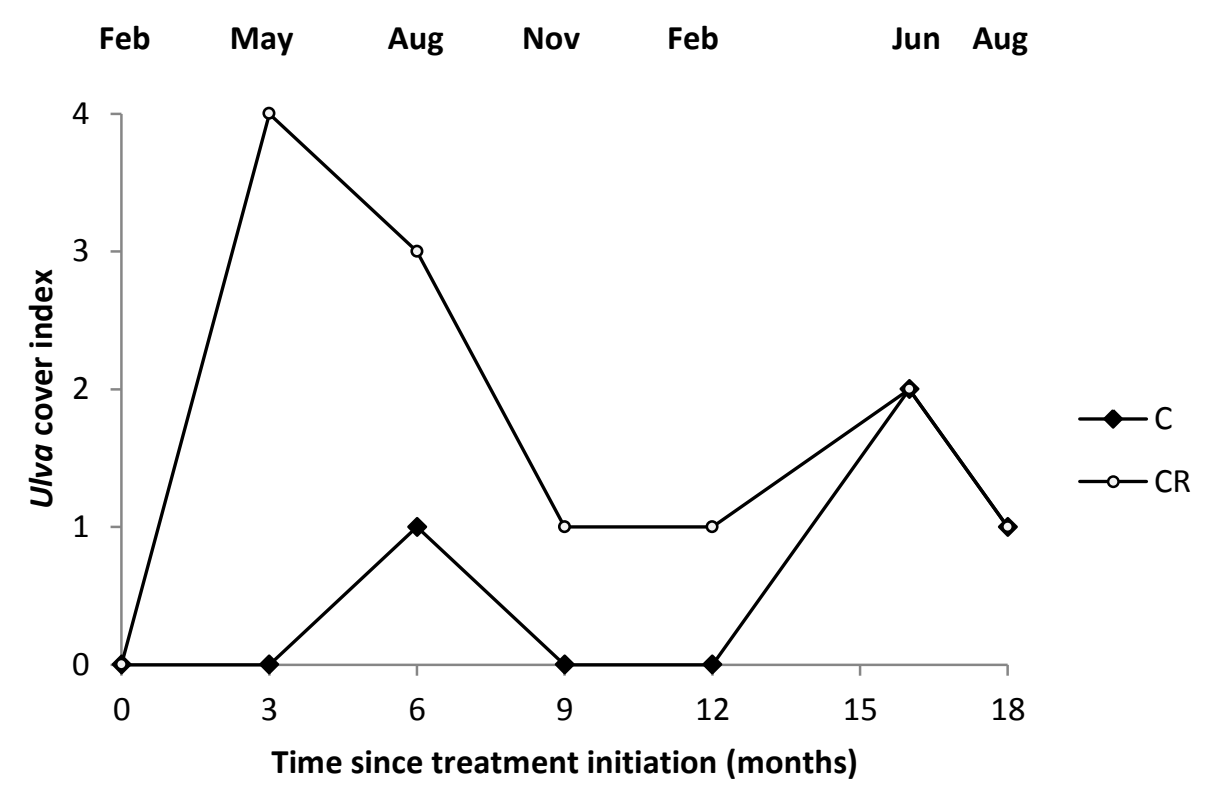

Figure 7: Temporal variation of the index of ephemeral green algae Ulva cover ((1: ]0-25\%], 2: ]2550\%], 3: ]50-75\%], 4: ]75-100\%]) in control (C) and canopy removed (CR) treatments 
Table 1: Mean ( $\pm \mathrm{SD}, n=5$ ) biomass $\left(\mathrm{g}_{\mathrm{DW}} \mathrm{m}^{-2}\right.$ ) of algae and animals in control $(\mathrm{C})$ and canopy removed (CR) quadrats at the end of the experiment

\begin{tabular}{lcc} 
& C & CR \\
\hline Algae & $3896.37 \pm 4218.39$ & $52.43 \pm 39.99$ \\
Algae without F. serratus & $54.48 \pm 36.49$ & $52.43 \pm 39.99$ \\
Animals & $356.87 \pm 263.88$ & $28.18 \pm 13.63$
\end{tabular}

